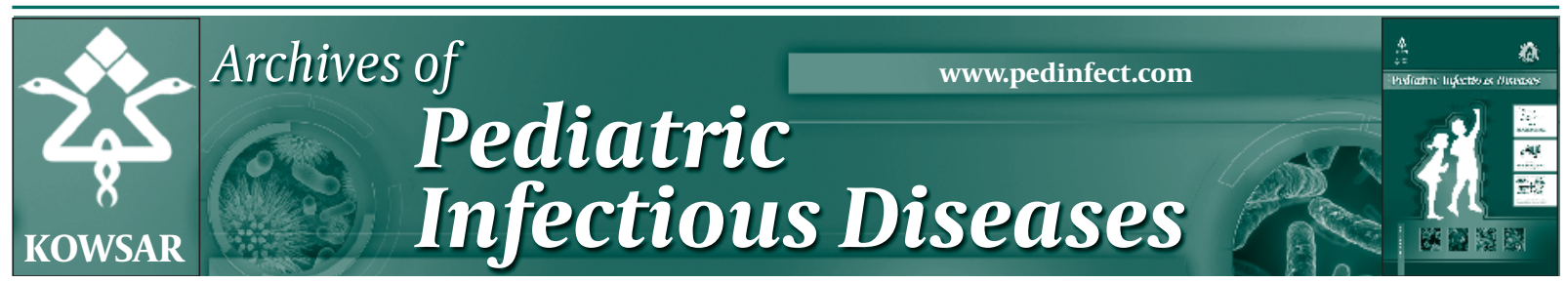

\title{
Childhood Tuberculosis in Kermanshah, Iran, During 10 Years
}

\author{
Keyghobad Ghadiri ${ }^{1}$, Farid Najafi ${ }^{2, *}$, Bahram Solimani ${ }^{3}$, Mansour Rezaei ${ }^{4}$, Mandana Afsha- \\ rian $^{5}$, Reza Akramipour ${ }^{6}$, Aliasghar Alipour ${ }^{7}$, Elham Shobiri $^{8}$ \\ ${ }^{1}$ Nosocomial Infections Research Center, Kermanshah University of Medical Sciences, Kermanshah, IR Iran \\ ${ }^{2}$ Department of Epidemiology, School of Population Health, Kermanshah University of Medical Sciences, Kermanshah, IR Iran \\ ${ }^{3}$ Kermanshah University of Medical Sciences, Kermanshah, IR Iran \\ ${ }^{4}$ Department of Biostatistics, Kermanshah University of Medical Sciences, Kermanshah, IR Iran \\ ${ }^{5}$ Department of Infectious Disease and Center for Infectious Diseases Research, Kermanshah University of Medical Sciences Kermanshah, IR Iran \\ ${ }^{6}$ Department of Pediatric Hematology, Kermanshah University of Medical Sciences, Kermanshah, IR Iran \\ ${ }^{7}$ Department of Neonatology, Kermanshah University of Medical Sciences, Kermanshah, IR Iran \\ ${ }^{8}$ Department of Radilogy, Kermanshah University of Medical Sciences, Kermanshah, IR Iran
}

*Corresponding author: Farid Najafi, Nosocomial Infections Research Center, Kermanshah University of Medical Sciences, Kermanshah, IR Iran. Tel: +988318384185, Fax: +98-8318386835, E-mail:farid_n32@yahoo.com.

\begin{abstract}
A B S T R A C T
Background: Tuberculosis in children still remains as one of the main causes of morbidity and mortality throughout the world.

Objectives: The aim of this study was to evaluate the epidemiological aspects of childhood tuberculosis in Kermanshah, Iran.

Patients and Methods: Medical records of all 150 patients aged 0-18 in Kermanshah district who were diagnosed according to WHO criteria for 10 years were retrospectively reviewed. As well as presenting demographic and clinical aspects of patients, we calculated notification rate. Results: $35 \%$ of cases were male and 65\% were female. Of total 150 tuberculosis cases, $56 \%$ were pulmonary and $44 \%$ were extra pulmonary. The most common symptoms were fever and cough. About $16 \%$ were asymptomatic. About $17 \%$ of patients had adult pulmonary tuberculosis in their families. The mean of the number of people living in a family (5.5) was similar in both pulmonary and extra pulmonary types. Except for year 2002, for all years the notification rate in girls was higher than that in boys. Over 10 years of study, the notification rate was 3.75/100,000 with no significant trend.

Conclusions: Based on our results, rate of diagnosis seemed under the expected range, in particular in children under 5 . Therefore, we recommend that authorities come up with programs that aim at raising awareness about the importance of diagnosis of pediatric tuberculosis.
\end{abstract}

Keywords: Tuberculosis; Child; Epidemiology

Copyright (c) 2013, Kowsar Corp.; Published by Kowsar Corp.

Article type: Brief Report; Received:14 Nov 2012, Revised: 10 Feb 2013, Accepted: 19 Apr 2013; DOI:10.812/pedinfect.9140

Implication for health policy/practice/research/medical education:

Although childhood tuberculosis constitutes $6 \%$ of all incident cases, because of no clear definition of such condition with non specific signs and symptoms, it usually missed and under diagnosed. Underestimation of real incidence of childhood tuberculosis in Kermanshah is an indication for better application of prevention and treatment measures in such groups. Such efforts can effectively help to control tuberculosis in whole population.

-Please cite this paper as:

Ghadiri K, Najafi F, Solimani B, Rezaei M, Afsharian M, Akramipour R, et al. Childhood Tuberculosis in Kermanshah, Iran, During 10 Years. Arch Pediatr Infect Dis. 2013;1(3):131-5. DOI: 10.812/pedinfect.9140

This is an Open Access article distributed under the terms of the Creative Commons Attribution License (http://creativecommons.org/licenses/by/3.0), which permits unrestricted use, distribution, and reproduction in any medium, provided the original work is properly cited. 


\section{Background}

Tuberculosis, one of the most common infectious diseases throughout the world, has been with human since antiquity. Tubercular decay has been found on the mummies of Egyptian pharaohs. From the world population, one third has been infected with mycobacterium tuberculosis and according to world health organization (WHO) about 8 million new cases and 2 million deathoccur annually worldwide. It is estimated that from 2000 until 2020, 1 million new people are infected with mycobacterium which will progress in 200 million and result in death in 35 million. AIDS will be responsible in 34\% of the new cases $(1,2)$. Each year about 888,400 of new cases and about $5 \%$ of deaths occurred in children under 15 years old (2). Despite to application of preventive and treatment measures, there has been an increase in the number of cases reported during the last decade of 20 th century $(2,3)$. Right now, $95 \%$ of the cases occur in developing countries where epidemics have the most effects and where there are limited resources for effective diagnosis and treatment. Even in many industrialized nations, most of the cases are observed among foreigners who are mostly from developing countries. Diagnosis in children is difficult as it is difficult to get the sputum's sample. Therefore, many cases of pediatric tuberculosis remain undiagnosed $(2,3)$. During 1985-1995, the United States experienced a tuberculosis increase at the rate of $22 \%$ among children under 4 , with the number of patients aged 5-14 growing by $66 \%$, witnessing the highest number of victims among the former group. The figure for tuberculosis in children rose from the mid-1980s until early 1990s $(4,5)$. Young children are most likely to be infected when exposed to active pulmonary tuberculosis, at a rate estimated of $20-40 \%$ for children aged $0-5$. However, pediatric tuberculosis is often ignored as it is paucibacillary and smear negative. In addition, there is no acceptable standard for diagnosis of pediatric tuberculosis. In less than half of the times the condition is diagnosed by positive culture and PCR. The fact that tuberculosis in adults has drawn much of the attention towards itself is another factor contributing to ignorance of pediatric tuberculosis. Nevertheless, the annual estimation of smearpositive pulmonary tuberculosis in children is somewhere around 1 million cases which results in higher rate of mortality and morbidity (6). While children contribute a significant proportion of the worldwide TB, reliable epidemiological data are rarely available from endemic area (7) and only few children in these areas have access to anti tuberculosis drugs (8). Children under 2 years old are at greater risk of progressing to disease within the first year after primary infection and although radiological signs after infection are detected in most of the cases only few of them receives medical care (2). However, children aged 4-15 are much more resistant to the contracting the infection $(2,3)$.

\section{Objectives}

With the paucity of information on the epidemiology of pediatrics tuberculosis, thepresent study aimed to investigate about the notified cases of tuberculosis among people agedo-18 years old in Kermanshah district over last 10 years.

\section{Patients and Methods}

Kermanshah is the central city of Kermanshah province located in Western Iran with a population of around one million people. For the purpose of this study we retrospectively reviewed all medical files of patients aged 0-18 years old with diagnosis of tuberculosis. Tuberculosis was diagnosed according to WHO criteria by using clinical manifestation, history of close contact with tuberculosis patients, sputum smear/culture,Tuberculin skin test, and Pathological finding (1-5). We included all smears positive and smear negative and extra pulmonary cases for the purpose of this study. All such patients have been referred to one of the rural or urban health centers of Kermanshah district or Kermanshah center for tuberculosis treatment within the period 1996-2005 and received anti-tuberculosis treatment based on physicians' decision. According to the rule from the ministry of health and treatment in Iran, all patients with tuberculosis will be treated without charge with drugs from governmental health facilities. For this reason, it is expected that tuberculosis data in Iran has a good coverage although under estimation of real numbers. We extracted all relevant demographic (age, sex, living area, family size and job) and clinical information (method of diagnosis, signs and symptoms) from medical records. In order to calculate the notification rate of tuberculosis (pulmonary, extra pulmonary and total) we divided the notified number of tuberculosis to estimated population of Kermanshah district sourced from national organization for civil registration. For the purpose of this study we used version 14. Data were analyzed using descriptive methods.

\section{Results}

Of total 150 patients 35\% of cases were male and 65\% were female. $56 \%$ of cases were pulmonary and $44 \%$ were extra pulmonary. Mean age and standard deviation for age were13.1 and 5.0, respectively. While $86 \%$ of the patients lived in urban areas $14 \%$ were from rural areas. The figure for pulmonary and extra pulmonary tuberculosis came out at $56 \%$ and $44 \%$, respectively. Mean age for the two types was almost the same at about 13 years. Most patients were between 15-18 years old (Table 1). Of the 150 cases with tuberculosis 16\% were asymptomatic and fever and cough were the most common symptoms (Table 2). The combination of cough, fever and sputum and cough and fever came out at $14.7 \%$ and $14 \%$ respectively. About $17 \%$ of patients had an adult patient in their families. The 
mean number of people living in a family was similar for both types (pulmonary and extra pulmonary) at around 5.5. However, $83 \%$ of patients had 4-7 people living in their families. Students made up $64 \%$ of total and most infected students were high school students. The percentage of students studying at elementary school, middle school and high school were $26 \%, 18.7 \%$ and $36 \%$ respectively.

Table 1. Distribution of Pulmonary and Extrapulmonary Tuberculosis by age Groups, Kemanshah, Iran-1996-2005

\begin{tabular}{|c|c|c|c|c|}
\hline & & \multicolumn{2}{|c|}{ Type of Disease } & \multirow[t]{2}{*}{ Total } \\
\hline & & $\begin{array}{l}\text { Pulmonary No. } \\
\text { (\%) }\end{array}$ & $\begin{array}{l}\text { ExtraPulmonary } \\
\text { No. (\%) }\end{array}$ & \\
\hline \multicolumn{5}{|l|}{ Age, y } \\
\hline & $<5$ & $8(57.1)$ & $6(42.9)$ & 14 \\
\hline & $5-14$ & $26(50.0)$ & $26(50.0)$ & 52 \\
\hline & $15-18$ & $50(59.5)$ & $34(40.50$ & 84 \\
\hline Total & & $84(56.0)$ & $66(44.0)$ & 150 \\
\hline
\end{tabular}

Smear with $58 \%$ and radiography with $32 \%$ represented the most common methods for diagnosis. Table 2 shows the incident rate of pulmonary and extra pulmonary tuberculosis in both sexes in different years. Accordingly, the notification rate of both pulmonary and extra pulmonary was higher in girls than boys. The overall notification rate of tuberculosis was 3.75 in 100000 populations in Kermanshah (Table 3) with no significant secular trend.

Table 2. Frequency of Signs and Symptoms Among People With Tuberculosis Aged 0-18 ${ }^{\mathrm{a}}$, Kermanshah, Iran-1996-2005

\begin{tabular}{lll}
\hline Signs and Symptoms & No. & Percent \\
\hline Asymptomatic & 24 & 16.0 \\
\hline 1-cough & 41 & 27.3 \\
\hline 2-sputum & 12 & 8.0 \\
\hline 3-dyspnea & 13 & 8.7 \\
\hline 4 -fever & 49 & 32.7 \\
\hline 5-sweating & 4 & 2.7 \\
\hline 6-arthralgia & 7 & 4.6 \\
\hline Total & 150 & 100 \\
\hline
\end{tabular}

${ }^{\mathrm{a}}$ All numbers show the frequency of signs and symptoms alone and incombination with each other

Table 3. Notification Rate of Tuberculosis in Children Aged 018 by Sex, Type of Tuberculosis and Year of Study, Kermanshah, Iran-1996-2005

\begin{tabular}{lllllllllll}
\hline Year & \multicolumn{3}{c}{ Pulmonary Tuberculosis } & \multicolumn{2}{c}{ Extra Pulmonary Tuberculosis } & \multicolumn{3}{c}{ Total } \\
\hline & Boys & Girls & Total & Boys & Girls & Total & Boys & Girls & Total \\
\hline $\mathbf{1 9 9 6}$ & 0.48 & 3.01 & 1.71 & 2.38 & 2.01 & 2.20 & 2.85 & 5.02 & 3.91 & \\
\hline $\mathbf{1 9 9 7}$ & 1.88 & 3.98 & 2.90 & 0.94 & 3.48 & 2.17 & 2.82 & 7.47 & 5.07 \\
$\mathbf{1 9 9 8}$ & 2.32 & 2.46 & 2.39 & 0.46 & 3.93 & 2.15 & 2.79 & 6.39 & 4.54 \\
\hline $\mathbf{1 9 9 9}$ & 1.41 & 1.98 & 1.69 & 1.41 & 0.99 & 1.20 & 2.82 & 2.97 & 2.89 \\
\hline $\mathbf{2 0 0 0}$ & 1.87 & 1.96 & 1.91 & 0.47 & 1.47 & 0.96 & 2.33 & 3.44 & 2.87 \\
\hline $\mathbf{2 0 0 1}$ & 0.46 & 4.39 & 2.38 & 0.46 & 1.46 & 0.95 & 0.93 & 5.85 & 3.33 \\
$\mathbf{2 0 0 2}$ & 3.23 & 2.29 & 2.78 & 2.15 & 2.29 & 2.22 & 5.39 & 4.58 & 5.00 \\
\hline $\mathbf{2 0 0 3}$ & 1.59 & 2.81 & 2.19 & 0.00 & 4.50 & 2.19 & 1.59 & 7.32 & 4.37 \\
\hline $\mathbf{2 0 0 4}$ & 0.47 & 1.98 & 1.20 & 1.88 & 0.99 & 1.44 & 2.35 & 2.97 & 2.65 \\
\hline $\mathbf{2 0 0 5}$ & 0.54 & 3.41 & 1.94 & 1.08 & 1.14 & 1.11 & 1.62 & 4.55 & 3.04 \\
\hline Total & 1.41 & 2.83 & 2.10 & 1.12 & 2.21 & 1.65 & 2.53 & 5.04 & 3.75 \\
\hline
\end{tabular}

\section{Discussion}

Over the 10-year period, 150 cases of tuberculosis were found in Kermanshah with a notification rate of 3.75 in 100,000 population which not only falls below the WHO's estimated rate for Iran but also indicates incidence lower than mentioned in other studies carried out in Iran $(1,8,9)$. In addition, there were some differences in epidemiological aspects of disease. According to some studies in India annual infection risks in different part of their country were estimated between 1.3 to $1.7 \%$ (10-13). Also incidence rate was estimated in Indonesia 1-1.3\% (14), which indicates higher incidence in children compared to our study but in those studies incidence rates were estimated by analysis of PPD. Results of a study in southern part of Iran from 1998 until 2002 estimated an incidence rate of $122 / 100000$ and 202/100000 for the Iranians and the Afghans respectively. The proportion of positive smear to negative smear in pulmonary or extra pulmonary tuberculosis was $1.46 \%$ in this study (9). On the other hand, according to a study in suburban Ahvaz in Iran, the incidence risk was $5 \%$, with the rate of positive smear at 25/100000 and prevalence of active tuberculosis in children at 75/100000 (15), which shows a higher prevalence compared to our study. Based on our findings, while the boys represented $35 \%$ of the total, the girls made up the 
bulk at $65 \%$, indicating a ratio of around 2:1. This contrasts with most other studies which indicate no sex reference for pediatric tuberculosis $(2,16)$.

We found that children aged 15-18 had the highest incidence, placing the 5-14 year-olds on the second. However, in most studies, the ages 5-14 has been described as safe age for tuberculosis and most cases are reported in younger adults and children under 5 (2-4). This may be due to under diagnosed of tuberculosis in young children because getting a specimen like sputum for laboratory is difficult in this age group. Although most of our patients lived in urban areas, the difference was almost proportionated to the population distribution in both areas. However rural areas had higher prevalenceof the disease based upon a study conducted in Bam, Iran (17).

In our study, the figure for pulmonary type came out at $56 \%$ and extra pulmonary type fell at $44 \%$ mark, indicating higher incidence of extra pulmonary type in children than the adults (Table 1) and also higher incidence rate of extra pulmonary rate in our study compare with most other studies $(2,3)$. Similarly, other studies from Iran reported a 71-82 percentage rate of pulmonary type among children $(17,18)$, much higher from what we have reported. Regarding the signs and symptoms presented with, while $16 \%$ of people were asymptomatic, fever, cough, simultaneous fever and cough and dyspnea were the most common symptoms. In fact studies from elsewhere have reported differently about the prevalence of signs and symptoms $(1,16,19-21)$. History of being exposed to an adult with positive smear pulmonary tuberculosis is the most important factor in contracting the disease and diagnosis in children. Although, our study showed that only $17.3 \%$ of the children had such member in their families in Brinza N study (22) 72\% of the patients had positive family record with $42 \%$ in Madagascar study (16). In another Study in Iran (23), 4.8\% of people encountered infected people contracted pulmonary tuberculosis.The cause of the lower ratio in our study and some studies in Iran may be due to inappropriate case finding in family member of patients. Regarding the method of diagnosis, sputum smear with $58 \%$ and radiography with $32 \%$ represented the most common methods. Considering the fact that only in $10-15 \%$ of children sputum smear comes out positive and $70 \%$ have negative culture, new methods need to be developed for diagnosis of tuberculosis among children. The cause of high rate of smear as being the most common method of diagnosis may be due to under diagnosis of childhood tuberculosis in our region. When many tuberculosis children were not diagnosed sputum can became the most common diagnostic method. Although Brinze N's study (22) showed that $24.8 \%$ of diagnosed were made by culture, in our study, only 4 cases were detected through this method. Although there were no secular trends in notification of tuberculosis over the period of study, it reached to the peak in 1997 and 2002.
Conclusion: According to our study there is suboptimal diagnosis of tuberculosis in children and there are also some differences in epidemiological features of disease among affected children. Physicians as well as public health section should consider TB among children more seriously both for diagnosis and treatment.

\section{Acknowledgements}

We thanks tuberculosis center of Kermanshah University of medical sciences.

\section{Authors' Contribution}

Keyghobad Ghadiri : Design the study, supervision for preparing first draft and final draft

\section{Financial Disclosure}

Farid Najafi: Analysis of data, contribution to first draft and final draft, corresponding author, Bahram Solimani: collecting data, writing the first draft, contribution to final draft, Mansour Rezaei: Analaysis of data, preparing the proposal, contribution to first and final draft, Mandana Afsharian: Add expertise to paper with contribution to final draft, Reza Akramipour: Add expertise to paper, contribution to first and final draft, Aliasghar Alipour: Add expertise to paper, contribution to first and final draft, Elham Shobiri: Add expertise to paper, contribution to first and final draft.

\section{Funding/Support}

This project was supported by a grant from Kermanshah University of Medical Sciences and was part of thesis of Dr Bahram Solaimani for graduation from Medical School

\section{References}

1. Mubarik M, Nabi B, Ladakhi GM, Sethi AS. Childhood tuberculosis (Part-I). Epidemiology, pathogenesis, clinical profile. JK Pract. 2000;7(1):12-5.

2. Starke JR. Tuberculosis. In: Feigin RD, editor(s). Textbook of pediatrics infectious diseases. 6th ed. Phladelphia: Saunders, Elsevier; 2009. p. 1426-69.

3. Starke JR, MMunoz F. Tuberculosis. In: Kliegman RR, Behrman RB, Jenson HB, Stanton BF, editor(s). Nelson textbook of pediatrics. 18th ed. Illustrations : Saunders; 2007.

4. Lobato MN, Cummings K, Will D, Royce S. Tuberculosis in children and adolescents: California, 1985 to 1995. Pediatr Infect Dis J.1998;17(5):407-11.

5. Epidemiology. Available from: http://www.who.int/topics/epidemiology/en/.

6. Marais BJ, Gie RP, Schaaf HS, Hesseling AC, Enarson DA, Beyers N The spectrum of disease in children treated for tuberculosis in a highly endemic area. Int J Tuberc Lung Dis. 2006;10(7):732-8.

7. Marais BJ, Gie RP, Hesseling AC, Schaaf HS, Lombard C, Enarson DA, et al. A refined symptom-based approach to diagnose pulmonary tuberculosis in children. Pediatrics. 2006;118(5):e1350-9.

8. Somu N, Vijayasekaran D, Ravikumar T, Balachandran A, Subramanyam L, Chandrabhushanam A. Tuberculous disease in a pediatric referral centre: 16 years experience. Indian Pediatr. 1994;31(10):1245-9.

9. Khazaei HA, Rezaei N, Bagheri GR, Dankoub MA, Shahryari K, 
Tahai A, et al. Epidemiology of tuberculosis in the Southeastern Iran. Eur J Epidemiol. 2005;20(10):879-83.

10. Chadha VK, Jagannatha PS, Vaidyanathan PS, Singh S. Annual risk of tuberculous infection in rural areas of Uttar Pradesh, India. Int J Tuberc Lung Dis. 2003;7(6):528-35.

11. Chadha VK, Kumar P, Satyanarayana AV, Chauhan LS, Gupta J, Singh S, et al. Annual risk of tuberculous infection in Andhra Pradesh, India. Indian J Tuberc. 2007;54(4):177-83.

12. Kolappan C, Gopi PG, Subramani R, Chadha VK, Kumar P, Prasad $\mathrm{VV}$, et al. Estimation of annual risk of tuberculosis infection (ARTI) among children aged 1-9 years in the south zone of India. Int J Tuberc Lung Dis. 2004;8(4):418-23.

13. Rao VG, Gopi PG, Yadav R, Subramani R, Bhat J, Anvikar AR, et al Annual risk of tuberculosis infection among tribal population of central India. Trop Med Int Health. 2008;13(11):1372-7.

14. Bachtiar A, Miko TY, Machmud R, Basri C, et al. Annual risk of tuberculosis infection in West Sumatra Province, Indonesia. Int $J$ Tuberc Lung Dis. 2008;12(3):255-61.

15. Alavi SM, Sefidgaran GH. Tuberculin survey among school-aged children in Ahvaz, Iran, 2006. Int IInfect Dis. 2008;12(4):406-9.

16. Boileau P, Grill J, Rabarijaona L, Andriamparany M, Guyon P,
Auregan G. [Tuberculosis in children in Madagascar. 122 cases observed at the Soavinandriana-Antananarivo Hospital Center]. Arch Inst Pasteur Madagascar. 1995;62(1):31-6.

17. Rajabi A, Abaazari R. Eepidemiological evaluation oftuberculosis in Bam. Iran J Infect Dis. 2003;8(22):41-46.

18. Evauation of short course drug therapy for tuberculosis in pediatric ward of Imam khomini Hospital. Tehran Univ Med Sci J. 1999;2:49-52.

19. Jeong YJ, Lee KS. Pulmonary tuberculosis:uptodate imaging and management. ARJ. 2008;191:834-44.

20. Marais BJ. Childhood tuberculosis--risk assessment and diagnosis. S Afr Med J. 2007;97(10 Pt 2):978-82.

21. Savadkohi R, Arm Sh. Clinical and paraclinical manifestations of tubrculosis children inAmirkola,hospital Babol. Mazandarn Univ Med Sci J. 2002;11(30):48-52.

22. Brinza N, Mihaescu T. [Diagnostic difficulties in pulmonary tuberculosis in children]. Rev Med Chir Soc Med Nat Iasi. 2007;111(1):65-9.

23. Khalil Zadeh S, Baghaei N, Boloor Saz MR, Hakimi SM, Arami S, Velayati AA. [Screening of Tuberculosis in symptomatic close contact children]. Iran J Infect Dis. 2004;9(24):50-55. 